\title{
Targeted mutagenesis using CRISPR-Cas9 in the chelicerate herbivore Tetranychus urticae
}

\author{
Wannes Dermauw ${ }^{\mathrm{a}, *}$, Wim Jonckheere ${ }^{\mathrm{a}}$, Maria Riga ${ }^{\mathrm{b}}$, Ioannis Livadaras ${ }^{\mathrm{b}}$, John Vontas ${ }^{\mathrm{b}, \mathrm{c}}$, \\ Thomas Van Leeuwen ${ }^{\mathrm{a}, * *}$ \\ ${ }^{a}$ Laboratory of Agrozoology, Department of Plants and Crops, Faculty of Bioscience Engineering, Ghent University, Coupure Links 653, 9000, Ghent, Belgium \\ ${ }^{\mathrm{b}}$ Molecular Entomology Lab, Institute of Molecular Biology and Biotechnology (IMBB), Foundation for Research and Technology (FORTH), Nikolaou Plastira Street 100, \\ 70013, Heraklion, Crete, Greece \\ ${ }^{\mathrm{c}}$ Pesticide Science Laboratory, Department of Crop Science, Agricultural University of Athens, Iera Odos 75, 11855, Athens, Greece
}

\section{A R T I C L E I N F O}

\section{Keywords:}

Chelicerata

Genome editing

CRISPR

Cas9 ribonucleoprotein (RNP)

Acari

\begin{abstract}
A B S T R A C T
The use of CRISPR-Cas9 has revolutionized functional genetic work in many organisms, including more and more insect species. However, successful gene editing or genetic transformation has not yet been reported for chelicerates, the second largest group of terrestrial animals. Within this group, some mite and tick species are economically very important for agriculture and human health, and the availability of a gene-editing tool would be a significant advancement for the field. Here, we report on the use of CRISPR-Cas9 in the spider mite Tetranychus urticae. The ovary of virgin adult females was injected with a mix of Cas9 and sgRNAs targeting the phytoene desaturase gene. Natural mutants of this laterally transferred gene have previously shown an easy-toscore albino phenotype. Albino sons of injected virgin females were mated with wild-type females, and two independent transformed lines where created and further characterized. Albinism inherited as a recessive monogenic trait. Sequencing of the complete target-gene of both lines revealed two different lesions at expected locations near the PAM site in the target-gene. Both lines did not genetically complement each other in dedicated crosses, nor when crossed to a reference albino strain with a known genetic defect in the same gene. In conclusion, two independent mutagenesis events were induced in the spider mite T. urticae using CRISPR-Cas9, hereby providing proof-of-concept that CRISPR-Cas9 can be used to create gene knockouts in mites.
\end{abstract}

\section{Introduction}

Mites and ticks are members of the chelicerates, the largest group of terrestrial animals after insects. The two-spotted spider mite, Tetranychus urticae, and other spider mites are important crop pests worldwide. This herbivore species is at the extreme end of the generalist-to-specialist spectrum and can feed on a staggering 1100 plant species. Not surprisingly, it is currently reported as the 'most resistant' pest worldwide, as it developed resistance to more than 90 acaricides (Mota-Sanchez and Wise, 2019; Van Leeuwen and Dermauw, 2016; Van Leeuwen et al., 2015). In 2011, a $90 \mathrm{Mb}$ high-quality Sanger-sequenced genome became available for this species (Grbic et al., 2011). This allowed to disentangle some of the molecular mechanisms underlying resistance, whether to man-made pesticides or plant secondary compounds. The extreme adaptation potential of T. urticae was associated with specific gene expansions in known detoxification enzyme families, such as cytochrome P450 monooxygenases, glutathione-S-transferases, carboxyl-choline esterases, an unexpected repertoire of ABC and MFS transporters, and a proliferation of cysteine peptidases (Dermauw et al., 2013a, 2013b; Grbic et al., 2011; Santamaría et al., 2012). In addition, several genes acquired via horizontal gene transfer were uncovered and characterized, such as intradiol-ring cleavage dioxygenases, UDP-glycosyltransferases and a beta-cyanoalanine synthase (Schlachter et al., 2019; Snoeck et al., 2019b; Wybouw et al., 2012, 2014, 2018). Geneexpression studies have revealed large transcriptional differences between susceptible and resistant $T$. urticae strains, as well as after shortterm transfer or adaptation to new hosts (Dermauw et al., 2013b; Grbic et al., 2011; Snoeck et al., 2018; Wybouw et al., 2014, 2015; Zhurov et al., 2014). Furthermore, mite-plant interactions have been thoroughly examined (Alba et al., 2015; Bui et al., 2018; Jonckheere et al., 2016; Jonckheere et al., 2018; Martel et al., 2015; Santamaría et al., 2017, 2019; Wybouw et al., 2015; Zhurov et al., 2014). For instance,

\footnotetext{
* Corresponding author.

** Corresponding author.

E-mail addresses: wannes.dermauw@ugent.be (W. Dermauw), thomas.vanleeuwen@ugent.be (T. Van Leeuwen).
} 
some salivary proteins were shown to modulate plant defenses (Blaazer et al., 2018; Iida et al., 2019; Villarroel et al., 2016). The availability of a high-quality genome and new technical advances in high-throughput sequencing has also led to the development of a genetic mapping tool, bulked-segregant analysis, which allowed to map quantitative trait loci at high resolution (Bryon et al., 2017; Kurlovs et al., 2019; Snoeck et al., 2019a; Van Leeuwen et al., 2012; Wybouw et al., 2019). To conclude, the spider mite $T$. urticae has been an exceptional good model to study adaptation, owing to clear advantages in experimental manipulation, a small high-quality genome and the development of advanced genomic mapping tools.

However, the lack of tools for reverse genetics that can directly validate the involvement of genes and mutations in phenotypes of interest (and validate most of the work outlined above) has impeded critical advances in T. urticae molecular biology. RNA interference (RNAi) has dramatically accelerated scientific progress in different groups of insects (Scott et al., 2013), linking genes with phenotypes, but this technique is currently not always straightforward in mites (Kwon et al., 2016; Suzuki et al., 2017). Even more so, a recent technique, named clustered regularly interspaced short palindromic repeats (CRISPR) - CRISPR-associated protein 9 (Cas9), has revolutionized functional genetic work in many organisms (Zhang and Reed, 2017). Successful CRISPR-Cas9-mediated gene manipulation has been reported for a steadily increasing number of organisms in the arthropod subphyla Crustaceae (Gui et al., 2016; Martin et al., 2016; Nakanishi et al., 2014) and Hexapoda, including Diptera, Hymenoptera, Hemiptera, Coleoptera, Orthoptera and diverse Lepidoptera (see Sun et al. (2017) for a review, Kotwica-Rolinska et al. (2019); Xue et al. (2018), Le Trionnaire et al. (2019)), but not in the wide group of chelicerates. It is clear that the development of such method for directed, heritable gene editing is also crucial for the study of $T$. urticae and other mite and tick species.

The CRISPR-Cas9 technique currently usually consists of a twocomponent system with a small, easy to synthesize single guide RNA (sgRNA) and a bacterial nuclease (Cas9). It introduces double-stranded breaks in eukaryotic genomes, where the breaks can be repaired randomly (non-homologous end-joining, NHEJ) or based on a template (homology-directed repair). In order to obtain efficient heritable genome editing, Cas9 and sgRNA should be delivered to the nucleus of oocytes (Gantz and Akbari, 2018). In Drosophila, this is currently most easily accomplished by injecting sgRNAs in transgenic embryos expressing Cas9 under a germline-specific promotor (see for example Bajda et al. (2017) and Douris et al. (2016), and references in Korona et al. (2017)). Most current approaches with non-model organisms rely upon delivering the Cas9 ribonucleoprotein (RNP) complex (Cas9 protein + sgRNA) by embryonic microinjection (Chaverra-Rodriguez et al., 2018). However, within the chelicerates, successful embryo injection has not been accomplished yet, as injected chelicerate embryos die (Garb et al., 2018; Sharma, 2017). This is probably the main reason why transgenic mites and ticks have not yet been reported (with the exception of one older study that was never replicated (Presnail and Hoy, 1992)). An alternative method, avoiding the injection of eggs or embryos, is delivery of the Cas9 RNP complex to the germline by injecting the mother animals. Such approaches already proved to be successful for organisms such as nematodes (see for example Cho et al. (2013); Gang et al. (2017); Witte et al. (2015)) and insects (ChaverraRodriguez et al., 2018; Hunter et al., 2018; Macias et al., 2019). In this study, we used a similar approach, and injected virgin $T$. urticae females with a Cas9-sgRNA complex targeting the T. urticae phytoene desaturase gene, a laterally transferred gene essential for red pigmentation (Bryon et al., 2013, 2017). Among the progeny, we identified albino males and show that their albino phenotype was the result of CRISPRCas9 induced mutations in the phytoene desaturase gene, hereby providing proof-of-concept of the feasibility of CRISPR-Cas9 mediated genetic modification of mites.

\section{Material and methods}

\subsection{T. urticae strain}

The London strain (wild type, WT) of T. urticae is an outbred reference laboratory strain (Van Leeuwen et al., 2012) and was used for sequencing of the complete T. urticae genome (Grbic et al., 2011). All injection experiments were performed with mites from this strain. The Alb-NL strain used in complementation tests was previously described (Bryon et al., 2017). All strains were maintained as previously described (Riga et al., 2017) on Phaseolus vulgaris cv. "Prelude" at $26 \pm 1{ }^{\circ} \mathrm{C}, 60 \% \mathrm{RH}$ and $16: 8$ (light:dark) photoperiod.

\subsection{Recombinant Cas9 ribonucleoproteins and sgRNAs}

Recombinant Streptococcus pyogenes Cas9 protein containing multiple nuclear localization sequences (NLSs) (Alt- ${ }^{\circledast}$ S.p. Cas9 Nuclease V3, catalog \# 1081058) was purchased from Integrated DNA Technologies (Leuven, Belgium). Two guide sequences were designed using the CRISPOR website (Concordet and Haeussler, 2018, accessed in December 2018), with the following settings: T. urticae phytoene desaturase sequence (tetur01g11270, https://bioinformatics.psb.ugent. be/orcae/overview/Tetur) as target ("Step 1"), T. urticae London genome (GCA_000239435.1) as genome ("Step 2") and "20 bp NGG Sp Cas9" as Protospacer Adjacent Motif ("Step 3"). Based on the guide DNA sequences, $3 \mathrm{nmol}$ of single guide RNAs (sgRNA) was ordered. The ordered sgRNAs were synthetic sgRNAs (sgRNA1 and sgRNA2) from Synthego (Synthego Corporation, Menlo Park, California, USA), consisting of a 20 nt guide sequence ( $\mathrm{g} 1$ or g2) + 80-mer "Synthego scaffold".

\subsection{In vitro Cas9-sgRNA cleavage experiment}

Before performing in vivo CRISPR-Cas9 experiments with T. urticae, we tested whether the Cas9-sgRNA complex could cleave PCR products of tetur01g11270 in vitro. Primer3 (Rozen and Skaletsky, 2000) was used to design primers that amplify the tetur01g11270 regions that are targeted by the two sgRNAs (see above). An 895 bp region is amplified by the "tetur01g11270_DNA_1" primers (amplicon 1, containing the sgRNA1 cutting site), while "tetur01g11270_DNA_2" primers amplify a 699 bp region (amplicon 2, containing the sgRNA2 cutting site) (Table S1). T. urticae DNA was extracted from the WT strain using the Gentra Puregene Tissue Kit (QIAgen), according to the manufacturer's instructions and using 100 adult females as starting material. The PCR of tetur01g11270 fragments (amplicon 1 and 2) was conducted using the Expand $^{\mathrm{TM}}$ Long Range dNTPack (Sigma-Aldrich). PCR reaction mixtures were prepared according to the manufacturer's instructions and using the following temperature profile: denaturation for $2 \mathrm{~min}$ at $92{ }^{\circ} \mathrm{C}$, followed by five touch-down cycles of denaturation at $92{ }^{\circ} \mathrm{C}$ for $10 \mathrm{~s}$, annealing at $60{ }^{\circ} \mathrm{C}-1{ }^{\circ} \mathrm{C} /$ cycle for $15 \mathrm{~s}$ and elongation at $68^{\circ} \mathrm{C}$ for $1 \mathrm{~min}$. Next, 37 cycles of $92^{\circ} \mathrm{C}$ for $10 \mathrm{~s}, 55^{\circ} \mathrm{C}$ for $15 \mathrm{~s}$ and $68^{\circ} \mathrm{C}$ for $1 \mathrm{~min}$. After a final elongation of $68{ }^{\circ} \mathrm{C}$ for $5 \mathrm{~min}$, PCR products were checked by agarose gel electrophoresis, and purified using the EZNA ${ }^{\circledast}$ Cycle Pure Kit (Omega Bio-Tek). The in vitro digestion protocol was performed as described by the IDT Alt-R CRISPR-Cas9 System Protocol (version September 2019, available at https://eu.idtdna.com/pages/support/ guides-and-protocols, document ID\# CRS-10096-PR 09/19), with some modifications. Briefly, the Cas9 RNP complex was created by combining $2.5 \mu \mathrm{l}$ sgRNA (10 $\mu \mathrm{M}$ stock in TE buffer, pH 7.5), $0.4 \mu$ l Alt-R S.p. Cas9 enzyme ( $62 \mu \mathrm{M}$ stock) and $22.1 \mu \mathrm{l}$ Cas 9 dilution buffer (30 mM HEPES, $150 \mathrm{mM} \mathrm{KCl}, \mathrm{pH}$ 7.5). For negative controls, sgRNA was replaced by TE. After incubation for $10 \mathrm{~min}$ at $\mathrm{RT}$, the in vitro digestion reaction was assembled at RT as follows: $2 \mu \mathrm{l} 10 \times$ Cas9 Nuclease Reaction Buffer (200 mM HEPES, $1 \mathrm{M} \mathrm{NaCl}, 50 \mathrm{mM} \mathrm{MgCl}_{2}, 1$ mM EDTA, pH 6.5), $4 \mu \mathrm{l}$ Cas9 RNP (from previous step), $10 \mu \mathrm{l}$ DNA substrate (amplicon 1 or 2 , $50 \mathrm{nM}$ stock) and $4 \mu \mathrm{l}$ of water. The reaction mixture was incubated for 
$90 \mathrm{~min}$ at $37{ }^{\circ} \mathrm{C}$, after which $2 \mu \mathrm{l}$ proteinase K (Sigma-Aldrich; $10 \mathrm{mg}$ / $\mathrm{mL}$ ) was added, and the DNA substrate was released from the Cas9 endonuclease by incubating for $10 \mathrm{~min}$ at $56{ }^{\circ} \mathrm{C}$. Subsequently, the digestion was analyzed using gel electrophoresis, in which $15 \mu$ l reaction mixture was loaded on gel.

\subsection{In vivo Cas9-sgRNA cleavage experiment}

\subsubsection{Cas9-sgRNA injection mix}

The Cas9-sgRNA injection mix was prepared as indicated in Table $\mathrm{S} 2$. The final concentration of the Cas9 protein in the injection mix was $4.85 \mu \mathrm{g} / \mu \mathrm{L}(29.61 \mu \mathrm{M})$. Stock solution of each sgRNA was prepared by dissolving $3 \mathrm{nmol}$ of sgRNA into $30 \mu \mathrm{L}$ of RNAse-free water. sgRNAs were added to the injection mix in a 1:3 Cas9:sgRNA molar ratio and $0.49 \mathrm{mM}$ of chloroquine was also included in the injection mix. The Cas9-sgRNA injection mix was incubated at $37{ }^{\circ} \mathrm{C}$ for $10 \mathrm{~min}$, and finally, the injection mix was centrifuged at $4{ }^{\circ} \mathrm{C}$ for $10 \mathrm{~min}$ at $10,000 \mathrm{~g}$ and kept on ice until injection.

\subsubsection{Injection of T. urticae female mites}

Female mites of the WT strain were allowed to lay eggs on the upper part of bean leaves on wet cotton in a Petri dish. After eight days, teliochrysalis females were transferred to another leaf disk and allowed to molt. After another one to four days, these unfertilized females were used for injections. Agar plates were made by dissolving $15 \mathrm{~g}$ of agar into $500 \mathrm{~mL}$ of cherry juice (for color contrast, brand "Eviva") and subsequently heated until boiling. An agar "platform" was made by adding two glass microscope slides $(26 \times 76 \mathrm{~mm}, 1.1 \mathrm{~mm}$ thick; APTACA, Canelli, Italy), attached to each other by double-sided tape, into a Petri dish immediately after pouring the agar plates. After solidification of the agar, the microscope slides were removed, and the agar plate was cut in two along the length of the microscope slide (Fig. S1). Unfertilized females were aligned on the agar platform, with their dorsal and right lateral side in contact with the agar (Fig. 1). Injection

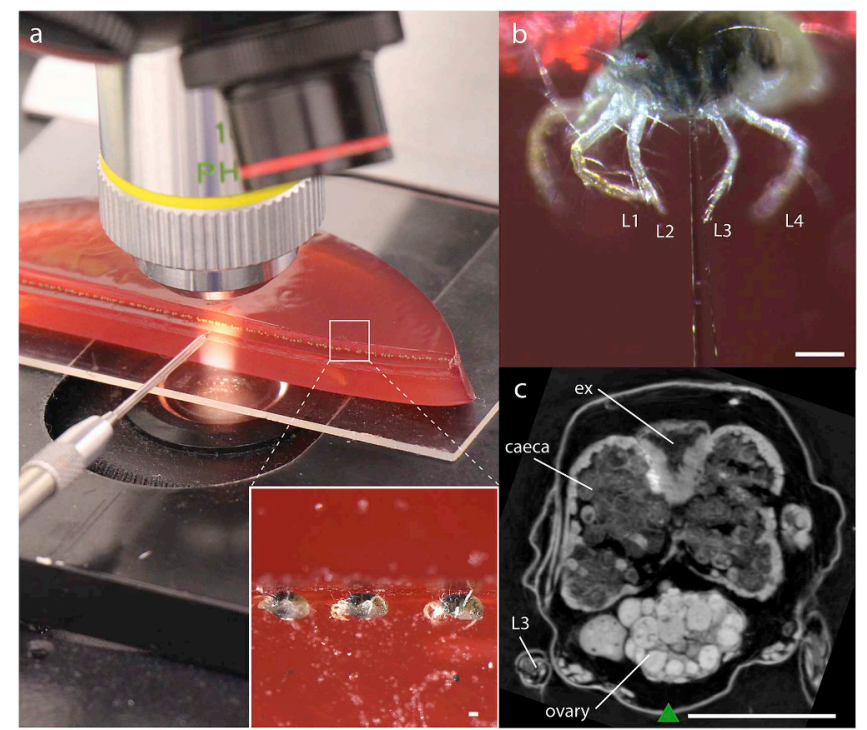

Fig. 1. Cas9-sgRNA micro-injection of T. urticae.

(a) setup for injection of $T$. urticae females: virgin females were aligned on an "agar platform" and injected under a microscope; insert: mites aligned on the agar platform, (b) females approximately injected at the third pair of legs: L1, L2, L3 and L4 refer to the 1st, 2nd, 3rd and 4th pair of legs, respectively (c) virtual cross-section at the third pair of legs; this section was obtained from a previously performed submicron CT scan of a $T$. urticae adult female (Jonckheere et al., 2016); a green triangle points towards Cas9-sgRNA injection location; L3: third pair of legs, ex = excretory organ. Scale bar in each panel represents $0.1 \mathrm{~mm}$. (For interpretation of the references to color in this figure legend, the reader is referred to the Web version of this article.)
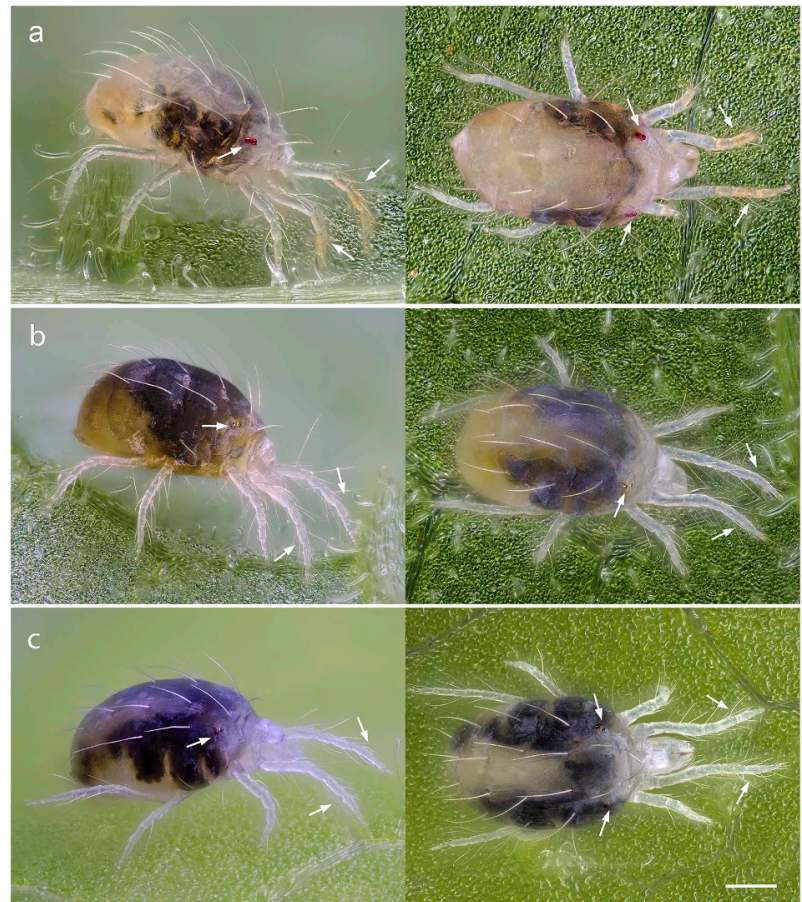

Fig. 2. Phenotypes of adult T. urticae females of the WT strain, CRISPR line $A$ and $B$.

Shown are (a) T. urticae pigmentation of the WT strain, (b) albino phenotype of CRISPR line A and (c) albino phenotype of CRISPR line B. Arrows indicate red eye spots or distal red-orange pigmentation in the front legs of WT mites, which are absent in albino females of line A, while females of line B have no red pigmentation in the front legs but slight traces of red pigmentation (barely visible here) are present in the eyes. Left: lateral view; Right: dorsal view. Scale bar represents $0.1 \mathrm{~mm}$. (For interpretation of the references to color in this figure legend, the reader is referred to the Web version of this article.)

needles were pulled from Clark capillary glass (borosilicate with filament: $1.0 \mathrm{~mm}$ (outside diameter, OD) x 0.58 (inner diameter, ID) $\mathrm{x}$ 100 mm (length); catalog \#W3 30-0019/GC100F-10 (Harvard Apparatus Ltd, Holliston, Massachussets, USA)) using a P97-micropipette needle puller (Sutter Instruments, Novato, California, USA), with the following settings "Heat: 510, Pull: 20, Velocity: 90, Time: 250" (Fig. S2). Mites were injected under a Leitz BIOMED Microscope (Wild Leitz/ Leica, Wetzlar, Germany) and with a mechanical micromanipulator (Leitz/Leica, Wetzlar, Germany) that holds the injection needle (Fig. 1). Approximately 3-5 $\mathrm{nl}$ of Cas9-sgRNA injection mix was injected in the ovary, near the third pair of legs, using an IM 300 Microinjector (Narishige, London, UK). Two batches (A and B) of mites were injected. Each batch of injected mites was transferred to a separate leaf disk and allowed to lay eggs. After $24 \mathrm{~h}$, the injected females were transferred to a new leaf disk and allowed to lay eggs again. The male haploid progeny of injected females (on four leaf disks in total ( 2 batches: A and B, 2 time-points: $0-24 \mathrm{~h}$ and $24-48 \mathrm{~h}$ )) was visually screened for the albino phenotype beginning 3 days after egg deposition.

\subsection{Mode of inheritance of albino phenotype and generation of homozygous albino CRISPR lines $A$ and $B$}

Albino sons from Cas9-sgRNA injected females from the A and B batch were isolated on bean leaf disks (one male per leaf disk) and allowed to mate with three to five virgin females of the parental strain (London, WT). Mated females were allowed to lay eggs for six days on the leaf disk (disk 1) and were discarded afterwards. Next, three $F_{1}$ teliochrysalis females that developed from eggs on disk 1, were transferred to a separate leaf disk, allowed to hatch, and to lay eggs for four days (disk 2). These virgin $F_{1}$ females (from disk 2) were then 


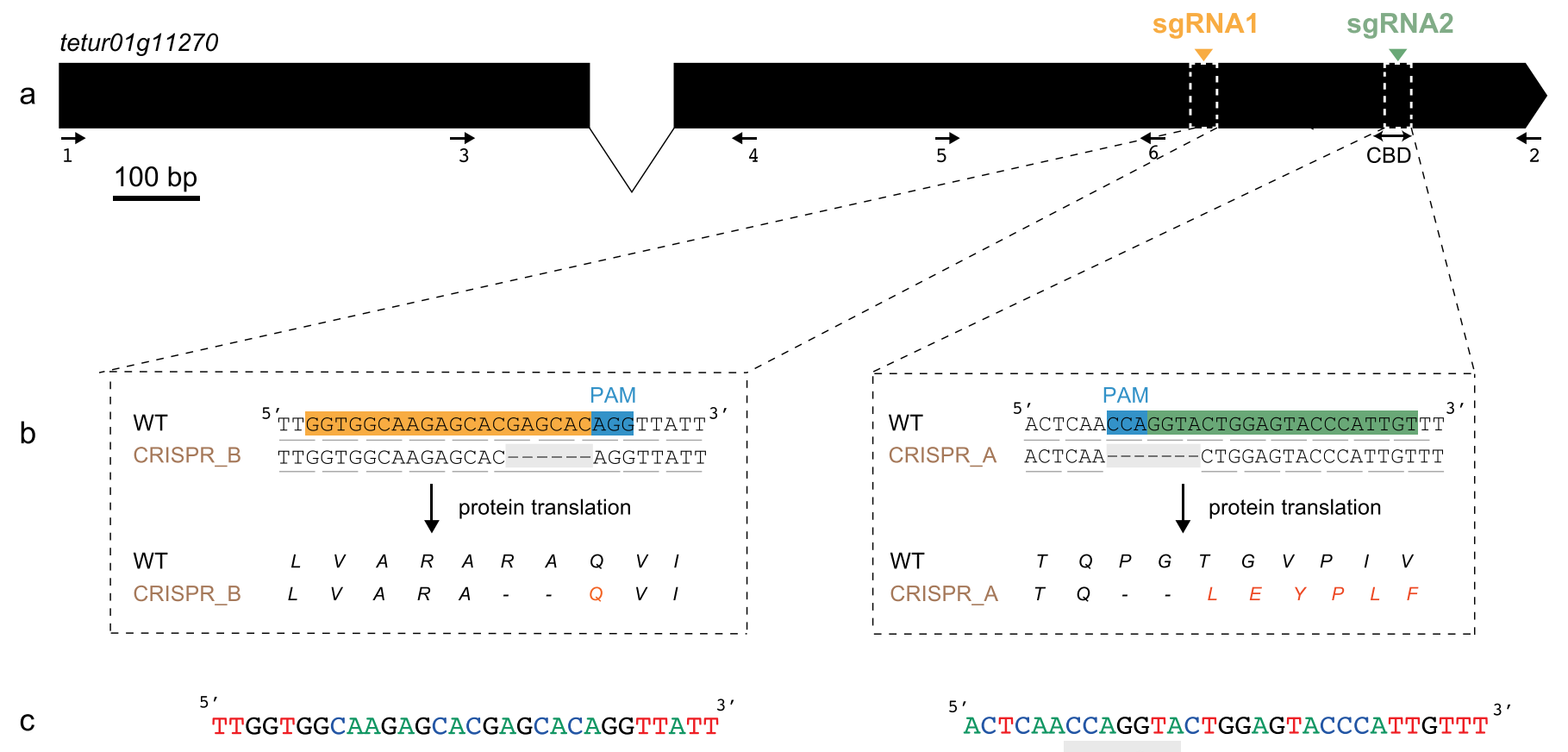

WT

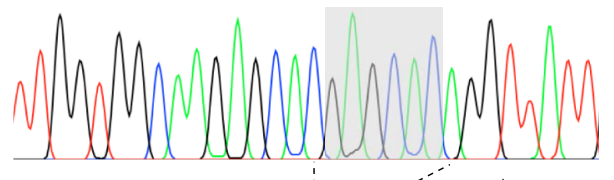

CRISPR_B

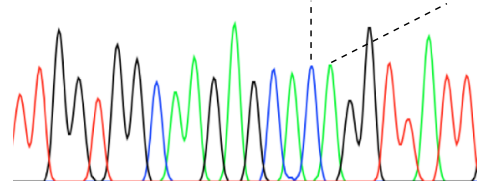

WT

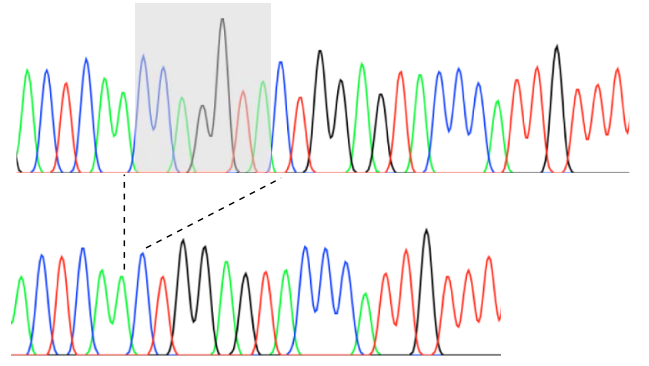

d

\begin{tabular}{|c|c|}
\hline \multirow{5}{*}{ Mites } & Tu WT \\
\hline & Tu CRISPR_B \\
\hline & $\mathrm{Te}$ \\
\hline & Pc \\
\hline & $\mathrm{Pu}$ \\
\hline \multirow{3}{*}{ Insects } & Md \\
\hline & Ap \\
\hline & Mp \\
\hline \multirow{3}{*}{ Fungi } & $\mathrm{Pb}$ \\
\hline & $\mathrm{Ff}$ \\
\hline & $\mathrm{Nc}$ \\
\hline \multirow{2}{*}{ Bacteria } & Rs \\
\hline & $\mathrm{Pa}$ \\
\hline
\end{tabular}

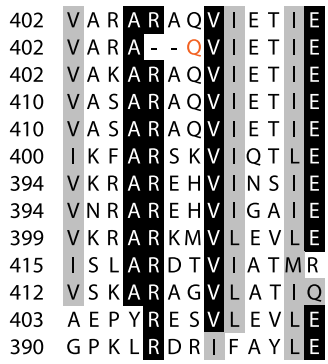

\begin{tabular}{ll}
\multicolumn{1}{c}{} & Tu WT \\
& Tu CRISPR_A \\
Mites & Te \\
& $\mathrm{Pc}$ \\
& $\mathrm{Pu}$ \\
\hdashline & $\mathrm{Md}$ \\
Insects & $\mathrm{Md}$ \\
& $\mathrm{Ap}$ \\
& $\mathrm{Mp}$ \\
Fungi & $\mathrm{Pb}$ \\
& $\mathrm{Ff}$ \\
& $\mathrm{Nc}$ \\
Bacteria & $\mathrm{Rs}$ \\
& $\mathrm{Pa}$
\end{tabular}

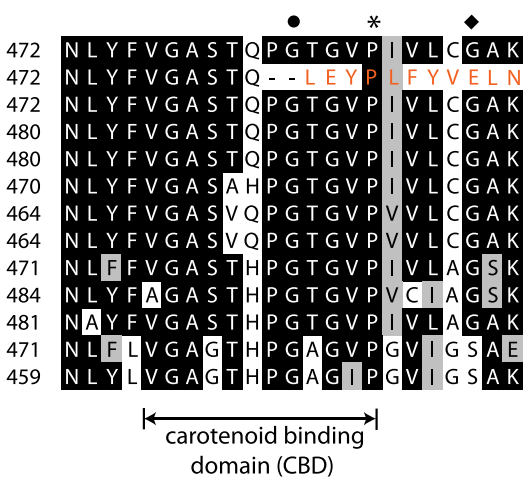

Fig. 3. Small indels detected in the phytoene desaturase gene (tetur01g11270) of T. urticae females of CRISPR line A and B.

(a) gene structure of tetur01g11270; the position of sgRNA1 and sgRNA2 cutting sites are indicated with an orange and green triangle, respectively; the position of the primers (1-6) used for PCR and sequencing of tetur01g11270 cDNA is indicated with arrows (Table S1); (b) indels found adjacent to the sgRNA cutting sites in tetur01g11270 of females of CRISPR line A or B; the guide sequence of sgRNA1 and the reverse complement of the sgRNA2 guide sequence are highlighted in orange and green, respectively, while the protospacer adjacent motif (PAM) is highlighted in blue; codons are underlined; (b-left) a 6 bp deletion (shaded gray) was found in tetur01g11270 of females of CRISPR line B, resulting in the deletion of two amino acids; (b-right) a 7 bp deletion (shaded gray) was found in females from CRISPR line A, causing a deletion of two amino acids in the carotenoid binding domain (CBD) and a frame shift changing translation; (c) chromatogram of the sequences displayed in (b), with the deletions present in the CRISPR lines shaded gray; (d) partial alignment of tetur01g11270 of CRISPR line B (d-left) and CRISPR line A (dright) with those of other tetranychid mites (Te, Tetranychus evansi; Pu, Panonychus ulmi; Pc, Panonychus citri), insects (Md, Mayetiola destructor; Ap, Acyrthosiphon pisum; Mp, Myzus persicae), Fungi (Pb, Phycomyces blakesleeanus; Ff, Fusarium fujikuroi; Nc, Neurospora crassa) and Bacteria (Rs, Rhodobacter sphaeroides; Pa, Pantoea ananatis). Accession numbers of all sequences can be found in Bryon et al. (2017) and in Fig. S6. A 75\% threshold was used for identity (black background) and similarity shading (grey background). (d-right) Mutations in P. blakesleeanus and F. fujikiroi that result in lowered phytoene desaturase activities are indicated with a black dot and rhombus, respectively (Prado-Cabrero et al., 2009; Sanz et al., 2002), while a Pro487Leu mutation that was identified in tetur01g11270 of T. urticae lines W-Alb-1/W-Alb-2, with young stages lacking pigment but red color being apparent in adults (Bryon et al., 2017), is indicated with an asterisk. (For interpretation of the references to color in this figure legend, the reader is referred to the Web version of this article.) 
transferred to another leaf disk and kept at $10{ }^{\circ} \mathrm{C}$ to increase their life span (disk 3). Subsequently, the number of albino and WT males was counted on disk 2 and an albino male from disk 2 was mated with its virgin mother (on disk 3) to generate a homozygous albino line (CRISPR lines $\mathrm{A}$ and $\mathrm{B}$ ). For these two lines, we also performed a complementation test on detached bean leaves. Briefly, 15 virgin (teliochrysalis) females from CRISPR line A or B were crossed with 30 males from the Alb-NL strain (Bryon et al., 2017). At least 100 resulting $F_{1}$ females were assessed for albinism. Last, we also performed a complementation test between 15 teliochrysalis females of CRISPR line A and 30 males of CRISPR line $B$ and scored albinism for at least $100 F_{1}$ females.

\subsection{DNA and RNA extraction from T. urticae CRISPR lines $A$ and $B$ and} PCR amplification of tetur01g11270

DNA was collected from five pooled females from lines A and B using the CTAB method previously described by Navajas et al. (1998). PCR of tetur01g11270 fragments was performed using the primers of the in vitro Cas9-sgRNA cleavage experiment (Table S1) and extracted DNA from lines A and B was used as template. The reactions consisted of $3 \mu \mathrm{l}$ $10 \times$ Buffer, $0.2 \mathrm{mM}$ of each dNTP, $0.33 \mu \mathrm{M}$ of each primer, $2 \mu 1$ template, 1U Kapa Taq DNA Polymerase (Kapa Biosystems) in a final volume of $30 \mu \mathrm{l}$ and with cycling conditions as follows: 5 min at $95{ }^{\circ} \mathrm{C}$ followed by 40 cycles of $30 \mathrm{~s}$ at $95{ }^{\circ} \mathrm{C}, 40 \mathrm{~s}$ at $53^{\circ} \mathrm{C}, 1 \mathrm{~min}$ at $72{ }^{\circ} \mathrm{C}$ and a final extension of $2 \mathrm{~min}$ at $72{ }^{\circ} \mathrm{C}$. PCR amplicons were verified on a $1.5 \%$ agarose gel, purified using the NucleoSpin ${ }^{\circledast}$ Gel and PCR Clean-Up kit (Macherey-Nagel) according to the manufacturer's instructions. Nucleotide sequences were determined in both strands of purified PCR products at the CeMIA sequencing facility (CEMIA, SA., Greece). Finally, RNA was extracted from mites of the A and B line. About 100 females were collected and RNA was extracted using the Qiagen RNeasy Plus mini Kit (Qiagen Benelux, Venlo, Nederland). One $\mu g$ of total RNA was used as template for synthesizing cDNA with the Maxima First Strand cDNA synthesis Kit for RT-qPCR (Fermentas Life Sciences, Aalst, Belgium). Primer3 (Rozen and Skaletsky, 2000) was used to design primers (tetur01g11270_cDNA primers) that amplify the coding sequence of the phytoene desaturase gene (tetur01g11270) (Table S1). PCRs were performed using the Expand Long Range dNTP Pack (Roche/ Sigma-Aldrich, Belgium). Reaction mixtures were prepared according to the manufacturer's instructions. The thermal profile consisted of denaturation for $2 \mathrm{~min}$ at $92{ }^{\circ} \mathrm{C}$, followed by 4 touch-down cycles of denaturation at $92{ }^{\circ} \mathrm{C}$ for $10 \mathrm{~s}$, annealing at $57{ }^{\circ} \mathrm{C}-1{ }^{\circ} \mathrm{C} /$ cycle for $15 \mathrm{~s}$ and elongation at $68{ }^{\circ} \mathrm{C}$ for $2.5 \mathrm{~min}$. Next, 40 cycles of $92{ }^{\circ} \mathrm{C}$ for $10 \mathrm{~s}$, $53{ }^{\circ} \mathrm{C}$ for $15 \mathrm{~s}$ and $68{ }^{\circ} \mathrm{C}$ for $2.5 \mathrm{~min}$. After a final elongation of $68{ }^{\circ} \mathrm{C}$ for 7 min, PCR products were purified using the E.Z.N.A. Cycle Pure kit (Omega Biotek) and Sanger sequenced by LGC genomics (Germany) with forward and reverse primers and four internal primers (Table S1).

\subsection{Imaging}

Images of adult females and immature stages of T. urticae were taken with an Olympus OM-D E-M1 mark II using a micro-objective on bellows (Nikon PB-4). The following micro-objectives were used: a Nikon M Plan 10x 160/0.25 (for females and larvae of WT strain and CRISPR line A), Nikon achromatic 10x 160/0.25 (for females of CRISPR line B) and a Nikon BD Plan ELWD 20x 210/0.4 (for larvae of CRISPR line B). Between 50 and 150 pictures were used for a focus stack. The open-source software align_image_stack (https://www.systutorials. com/docs/linux/man/1-align_image_stack/) and Enfuse (http:// software.bergmark.com/enfuseGUI/Main.html) were used to generate the focus stack, while Darktable (https://www.darktable.org/) was used for pre-and posttreatment of images. Images of adult males were taken using a stereomicroscope (Leica S8 Apo, Witzlar Germany) and a Leica DFC295 camera.

\section{Results}

\section{1. sgRNA guide sequence design and in vitro Cas9-sgRNA cleavage}

Guide sequences were designed using the CRISPOR website as described above. The first guide sequence ( $\mathrm{g} 1,5^{\prime}$-GGTGGCAAGAGCACG AGCAC- $3^{\prime}$ ) was selected because it had the highest "out-of-frame" score (the higher this score, the more deletions have a length that is not a multiple of three (Bae et al., 2014)) while the other guide sequence (g2, 5'-ACAATGGGTACTCCAGTACC-3') was selected because it was located in a region postulated to encode the carotenoid binding domain of the phytoene desaturase (Armstrong et al., 1989; Sanz et al., 2002). Finally, both guide sequences had a predicted off-target count of zero. In vitro Cas9-sgRNA cleavage of PCR amplicons of tetur01g11270 resulted in the correct in silico-predicted digestion pattern: amplicon 1 (895 bp) was cleaved into a 537 and 398 bp fragment, while amplicon 2 (699bp) was cleaved into a 197 bp and 502 bp fragment (Fig. S3).

\subsection{In vivo Cas9-sgRNA experiment}

\subsubsection{Screening of albino male progeny and generation of CRISPR lines A and $B$}

Two batches of virgin females were injected in the ovary: 245 mites in batch "A" and 177 mites in batch "B". Twenty-four hours after injection, the percentage of alive females was recorded as $78.4 \%$ and $71.8 \%$, respectively. Injected females were allowed to lay eggs for $24 \mathrm{~h}$, were placed on new arenas, and allowed to lay eggs for another $24 \mathrm{~h}$. The number of eggs on each arena was, approximately, 650 and 900 for batch A and 260 and 650 for batch B after $24 \mathrm{~h}$ and 24-48 h, respectively. After hatching, we screened for male larvae lacking pigment. In the arenas with eggs deposited within $24 \mathrm{~h}$ after injection, we found one alive albino male in both batch A and B (Table 1), while in batch A thirteen specimens with albino phenotype were detected in larvae/ protochrysalises resulting from eggs deposited between 24 and $48 \mathrm{~h}$ after injection. However, none of these larvae/protochrysalises developed into adults. From both batches, the alive albino male was isolated, allowed to develop to the adult stage and crossed to obtain homozygous stable lines named CRISPR line A and B, respectively, which were characterized further. All life stages of CRISPR line A lacked red pigments (,Fig. 2, Fig. S4, Fig. S5). In contrast, only immature stages lacked red pigmentation in CRISPR line $\mathrm{B}$, while adult stages do show traces of red pigmentation in the eyes, especially visible in the males, but lack red pigmentation in the front legs (Fig. 2, Fig. S4, Fig. S5).

\subsubsection{Mode of inheritance and complementation test of albino phenotype in} CRISPR lines $A$ and $B$

The genetic basis of the albino phenotype found in the two sons of Cas9-sgRNA injected virgin females was determined by crossing with

Table 1

CRISPR-Cas9 efficiency.

\begin{tabular}{|c|c|c|}
\hline & \multicolumn{2}{|c|}{ injection batch } \\
\hline & A & B \\
\hline number of injected virgin females & 245 & 177 \\
\hline number of injected virgin females alive after $24 \mathrm{~h}$ & 192 & 127 \\
\hline number of CRISPRed albino male offspring alive ${ }^{\mathrm{a}}$ & 1 & 1 \\
\hline number of dead albino male offspring ${ }^{\mathrm{b}}$ & 13 & 0 \\
\hline \% CRISPR-Cas9 success ${ }^{c}$ & 0.48 & 0.56 \\
\hline
\end{tabular}

a All alive albino male offspring was found in the egg batches deposited within 24 hours after injection.

b All dead albino male offspring was 1) either in the larva or protochrysalis stage and 2) was found in the egg batch deposited between 24 and 48 hours after injection.

c CRISPR-Cas9 success was calculated as the number of CRISPRed albino male offspring alive divided by the number of injected virgin females. 
Table 2

Inheritance and complementation tests

\begin{tabular}{|c|c|c|c|c|c|}
\hline \multirow[t]{2}{*}{ Crosses } & \multirow{2}{*}{$\begin{array}{l}\% \text { albino in } F_{1} \\
\delta\end{array}$} & \multicolumn{2}{|c|}{$\mathrm{F}_{2}$ haploid males } & \multirow[t]{2}{*}{$\chi^{2}$} & \multirow[t]{2}{*}{$\mathrm{P}$ value } \\
\hline & & ALB & WT & & \\
\hline \multicolumn{6}{|c|}{ Inheritance tests (female $\mathrm{x}$ male) ${ }^{\mathrm{a}}$} \\
\hline \multirow[t]{3}{*}{ WT x CRISPR A (rep1) } & 0 & 15 & 20 & 0.714 & 0.39802 \\
\hline & & 30 & 21 & 1.588 & 0.20758 \\
\hline & & 17 & 20 & 0.243 & 0.62187 \\
\hline \multirow[t]{3}{*}{ WT x CRISPR B (rep1) } & 0 & 25 & 20 & 0.556 & 0.45606 \\
\hline & & 12 & 14 & 0.154 & 0.69489 \\
\hline & & 28 & 27 & 0.018 & 0.89274 \\
\hline \multicolumn{6}{|c|}{ Complementation tests (female $\mathrm{x}$ male) ${ }^{\mathrm{b}}$} \\
\hline CRISPR A x Alb-NL ${ }^{c}$ & 100 & & & & \\
\hline CRISPR B x Alb-NL & 100 & & & & \\
\hline CRISPR A x CRISPR B & 100 & & & & \\
\hline
\end{tabular}

a An alive albino male - CRISPR A or CRISPR B - that was detected in the progeny of Cas9-sgRNA injected females of either batch A or B, respectively, was crossed with three to five females of the WT strain ( 1 male $\times 3-5$ females) and the F2 male progeny of three F1 virgin females was scored for wildtype (WT) or albino (ALB) males

b 15 females crossed with 30 males; $100 F_{1}$ females were screened for wildtype or albino phenotype.

c the Alb-NL strain is an albino T. urticae strain known to have an inactivating mutation in its phytoene desaturase gene (tetur01g11270) (Bryon et al., 2017).

the original WT strain. In all cases, $\mathrm{F}_{1}$ females of the resulting cross had normal body and eye color (Table 2). Together with the finding of an approximate 1:1 ratio of albino to WT phenotype in haploid $F_{2}$ sons produced by virgin $\mathrm{F} 1$ females, this strongly indicated that albinism was inherited as a monogenic recessive trait. In a complementation test, females of CRISPR line A and males of CRISPR line B were crossed, and the resulting $F_{1}$ females were all albinos indicating that the albino phenotype in both lines is caused by a disruption in the same gene (Table 2). Finally, we also crossed females of CRISPR lines A and B with males of strain Alb-NL, known to have an inactivating mutation in the phytoene desaturase gene (tetur01g11270) (Bryon et al., 2017), and found that all female $F_{1}$ progeny was albino. This failure to complement suggests that the albino phenotype of CRISPR lines A and B results from a mutation or disruption in tetur01g11270, the gene targeted by our Cas9-sgRNA experiment.

\subsubsection{Sequence analysis of tetu01g11270 in CRISPR lines $A$ and $B$}

DNA was extracted from CRISPR lines A and B and sequencing of PCR amplicons 1 and 2 revealed disruptions in the tetur01g11270 gene in both lines. Tetur01g11270 of CRISRP line B harbored a 6 bp deletion (nt 1117-1122 in WT reference sequence of tetur01g11270) that was located 6 bp upstream of the sgRNA1 PAM site, causing a loss of two amino acids (Arg406 and Ala407). Based on an alignment of phytoene desaturases of insects, fungi and bacteria (Fig. 3d) Arg406 is highly conserved.

CRISPR line A harbored a 7 bp deletion (nt 1444-1450 in WT reference sequence of tetur01g11270) that was located $4 \mathrm{bp}$ upstream of the sgRNA2 PAM site, resulting in the loss of two amino acids and a frame shift, changing translation (Fig. 3b) in the region of the carotenoid binding domain (Armstrong et al., 1989). To assure that the detected deletions were the only disruptions in the coding sequence of tetur01g11270 of CRISPR lines A and B, we sequenced the complete cDNA sequence of tetur01g11270 of both CRISPR lines and the WT strain. The cDNA sequence of CRISPR line B was, except for the $6 \mathrm{bp}$ deletion, $100 \%$ identical to that of the WT strain, while in the cDNA sequence of CRISPR line A, we found, next to the $7 \mathrm{bp}$ deletion, three non-synonymous single nucleotide polymorphisms (SNPs) (Fig. S6). All three non-synonymous SNPs resulted in favored substitutions according to Betts and Russell (2003). The amino acid changes "K- > Q" and "I$>$ V" (Fig. S6), caused by two non-synonymous SNPs, occur at a non- conserved amino acid position in the phytoene desaturase protein (Fig. S6 and Supplemental Figure S5 in Bryon et al. (2017)) and were also present in the WT strain at low frequency (data not shown). Last, the remaining non-synonymous SNP (resulting in an amino acid change "V- > I") was located downstream of the 7 bp deletion.

\section{Discussion}

CRISPR-Cas9 has revolutionized genome editing in metazoan species, including more and more arthropods (Kotwica-Rolinska et al., 2019; Reardon, 2019; Sun et al., 2017). For many arthropods, the orthologue of the Drosophila white or scarlet gene, ABC-transporters essential for eye pigmentation, has been used as a CRISPR-Cas9 target for establishing proof-of-principle of this technology (Bai et al., 2019; Ismail et al., 2018; Khan et al., 2017; Xue et al., 2018). A clear 1:1 orthologue of the white or scarlet gene could not be identified in T. urticae (Dermauw et al., 2013a) but recently it was shown that several mutations in a gene encoding a phytoene desaturase (tetur01g11270) caused an albino phenotype (lack of red pigment in the front legs and eyes) (Bryon et al., 2017). We took advantage of this discovery to design a CRISPR-Cas9 strategy with sgRNAs that target the phytoene desaturase of T. urticae (Fig. 3a). Next to the availability of a genetic marker with a clearly visible phenotype, efficient CRISPR-Cas9 further requires the delivery of the Cas9-sgRNA complex into the embryos in early development. As successful injection of mite and tick embryos has currently not been achieved (see Introduction), we followed a strategy previously applied for nematodes, mosquitoes and psyllids (ChaverraRodriguez et al., 2018; Cho et al., 2013; Gang et al., 2017; Hunter et al., 2018; Macias et al., 2019; Witte et al., 2015), and we injected T. urticae females in the ovary, assuming that the Cas9-sgRNA complex would be incorporated into the oocytes and developing embryos. In addition, the arrhenotokous reproduction system allowed us to inject unfertilized females of which the progeny consists of haploid males only. This allowed to immediately screen for an albino phenotype among the male progeny of injected females.

In this study, two batches (A and B) of virgin T. urticae females were injected with Cas9-sgRNA and in each batch one albino male was identified in the progeny developed from eggs laid by females less than $24 \mathrm{~h}$ after injection (Table 1). Subsequently, homozygous albino lines (CRISPR line A and B) were generated from these males and both the mode of inheritance and the complementation test revealed that disruptions in tetur01g11270 caused the albino phenotype (Table 2). The T. urticae genome harbors three copies of phytoene desaturase, and although tetur01g11270 is the only one with a clear role in pigment synthesis (Bryon et al., 2013, Bryon et al., 2017), one could question whether other T. urticae phytoene desaturase genes (tetur11g04820 and tetur11g04810, Grbić et al. (2011)) were also targeted. However, complementation tests with a characterized albino strain point to a single causal gene (Table 2). In addition, no off-target effects were predicted for guide sequences of both sgRNAs, and guide sequence regions differ significantly between tetur01g11270 and the other two phytoene desaturase genes (Fig. S7). Further, to assess whether the tetur01g11270 disruptions were caused by typical CRISPR-Cas9 events, we sequenced tetur01g11270 of CRISPR lines A and B at the DNA and cDNA level. Typical CRISPR-Cas9 events (Jinek et al., 2012) were identified in tetur01g11270 of both lines, with deletions located four to six base pairs upstream of the PAM site (Fig. 3b-c). Sequencing of the tetur01g11270 full-length coding sequence revealed that no other polymorphisms could be detected in CRISPR line B compared to the WT strain, while the tetur01g11270 coding sequence of CRISPR line A did contain three favored non-synonymous mutations (Fig. S6) of which two were also present in the WT strain. Altogether, this leaves no doubt that the Cas9-induced deletions in tetur01g11270 of CRISPR lines A and $\mathrm{B}$ are the underlying genetic basis of the albino phenotype. As both sgRNAs target the same gene and were injected together, it is interesting to note that none of the two albino CRISPR lines carried a large 
deletion between the sgRNA target sites. However, based on previous reports, sgRNAs seem not always to act together when using a dual sgRNA CRISPR-Cas9 approach (Chen et al., 2014; Kane et al., 2017) and given the low CRISPR-Cas9 efficiency (see below) it might not be surprising that we did not identify such event. Finally, subtle differences in the albino phenotype of each line could to some extent also be linked to the type of the Cas9-sgRNA induced deletion. In CRISPR line A, the $7 \mathrm{bp}$ deletion in tetur01g11270 causes a frameshift, thereby abolishing the carotenoid binding domain (Armstrong et al., 1989), resulting in the lack of pigment in all stages. In CRISPR line B, the $6 \mathrm{bp}$ deletion results in the loss of two amino acids, including a highly conserved arginine, but does not change translation (Fig. 3d). While immature stages of CRISPR line B lack pigmentation, traces of red pigmentation could be observed in the eyes of adult females and especially males, suggesting the 6 bp deletion in CRISPR line B can be considered as a hypomorphic mutation, i.e. causing only a partial loss of gene function (Muller, 1932).

Based on the total number of eggs that was laid by the injected females (1550 and 910 for batches A and B, respectively), the percentage of CRISPR-Cas9 transformed mite embryos is low (Table 1). Especially when compared to the CRISPR-Cas 9 efficiency in nematodes, where a mutation frequency of up to $17 \%$ in the $\mathrm{F}_{1}$ progeny can be obtained by injection of the Cas9-sgRNA complex into the gonads (Cho et al., 2013). Nevertheless, this frequency is similar to those in the first reports on genetic transformation of non-model insects (Catteruccia et al., 2000; Peloquin et al., 2000; Sumitani et al., 2003). Next, in contrast to the $24 \mathrm{~h}$ egg arenas of batch A and B, we could not obtain alive albino males from the $24-48 \mathrm{~h}$ egg arena of batch $\mathrm{A}$, as all thirteen detected albino larvae/protochrysalises did not develop into adulthood. To reinforce the likelihood that the observed albino males with identical phenotype in interval $24-48 \mathrm{~h}$ were caused by CRISPR-Cas9 events, the phytoene desaturase gene (or even better the genome) of these dead juvenile males should be sequenced. However, dead males in the larval/protochrysalis stage are merely $200 \mu \mathrm{m}$ in size and very hard to manipulate. If a CRISPR-Cas9 event would have occurred in these thirteen males, the decreased survival of the larvae/protochrysalises might have been the result of multiple accompanying off-target CRISPR-Cas 9 events at this time point after injection. However, given that the CRISPOR software predicted that both sgRNAs have zero offtarget effects, this seems unlikely. If only the number of injected females is taken into account, we obtained about one CRISPR-Cas9 transformant per 200 injected females. A frequency that is similar to the CRISPR-Cas9 efficiency in Anopheles mosquitoes using a similar methodology (effort efficiency (EEF) of $0.7 \%$ when using native Cas 9 , see Table 1 in Chaverra-Rodriguez et al., 2018), and that does allow to screen for visible phenotypic traits immediately. Arrhenotokous reproduction allows to immediately screen the males that can be directly used in dedicated crosses for fixation of the mutation. Which time point after injection is the most likely to result in CRISPRed embryos should be investigated and optimization of this timing could potentially increase screening efficacy. Because of this straightforward phenotype screening and mutation fixation, a 'CO-CRISPR' approach might be used to make this strategy also feasible for mutations without a visible phenotype. In this approach, injection mixtures would contain sgRNAs for both a marker gene and additional target-gene. It was previously shown for nematodes and insects that transformants with the visible marker have a much higher frequency of mutations in the target-gene (Dickinson and Goldstein, 2016; Farboud et al., 2019; Kane et al., 2017). This allows to preselect a number of progeny for further screening.

Previously, Bryon et al. (2017) used a similar CRISPR-Cas9 approach in an attempt to provide functional evidence of the role of mutations and deletions in tetur01g11270 in albinism. However, typical CRISPR-Cas9 events were not recorded. We hypothesized that this was most likely due to insufficient Cas9 RNP uptake by the oocytes. Here, we increased the Cas 9 protein concentration more than 5 -fold to
$4.85 \mu \mathrm{g} / \mu \mathrm{l}$. Furthermore, we used a different type of commercial Cas9 protein (containing multiple nuclear localization sequences (NLSs) while the commercial Cas9 protein of Bryon et al., 2017 contained only one C-terminal NLS), used only synthetic sgRNAs and added chloroquine to the injection mix, because it was recently shown that the addition of this compound improves CRISPR-Cas9 efficiency in mosquitoes (Chaverra-Rodriguez et al., 2018). Recent studies also hint toward other modifications that could improve CRISPR-Cas9 transformation efficiency, such as the use of other adjuvants like lipofectamine or branched amphiphilic peptide capsules (BAPC) (Adams et al., 2019; Hunter et al., 2018), or a shorter Cas protein (Cas12a/Cpf1 (Rusk, 2019)). Last, in a recent breakthrough study it was shown how ReMOT (Receptor-Mediated Ovary Transduction of Cargo) can be exploited to deliver Cas9 in oocytes after the injection of female mosquitoes. In this system, a "guide peptide" (P2C) mediates the transduction of the Cas9 RNP complex from the female mosquito hemolymph to developing oocytes. Although the principle of transformation should be transferable to other organisms, the peptide and protein identified in ChaverraRodriguez et al. (2018) have no homologues outside dipterans (flies and mosquitoes) and might not be readily transferable to mites and ticks.

To conclude, two independent mutagenesis events were induced in the spider mite T. urticae using CRISPR-Cas9, providing a proof-ofconcept that CRISPR-Cas9 is feasible in T. urticae and paving the way for functional studies in spider mites.

\section{Author contributions}

WD and TVL designed experiments; WD, WJ, MR and IL performed experiments. WD and TVL wrote the manuscript, with input from JV, MR and WJ. All authors reviewed the manuscript.

\section{Acknowledgements}

We thank Merijn Kant (University of Amsterdam, The Netherlands) for providing the Alb-NL strain, Gilles San Martin (Walloon Agricultural Research Centre CRA-W, Gembloux, Belgium) for taking photographs (Fig. 2, Fig. S4) of the different spider mite lines, Astrid Bryon (University of Wageningen, The Netherlands) for providing Fig. 1a and René Feyereisen (University of Copenhagen, Denmark/University of Ghent, Belgium) for critical reading of the manuscript. This work was supported by the European Union's Horizon 2020 research and innovation program [grant 772026-POLYADAPT to TVL and 773902-SuperPests to TVL and JV]. During this study WD was a postdoctoral fellow of the Research Foundation Flanders (FWO).

\section{Appendix A. Supplementary data}

Supplementary data to this article can be found online at https:// doi.org/10.1016/j.ibmb.2020.103347.

\section{References}

Adams, S., Pathak, P., Shao, H., Lok, J.B., Pires-daSilva, A., 2019. Liposome-based transfection enhances RNAi and CRISPR-mediated mutagenesis in non-model nematode systems. Sci. Rep. 9, 483.

Alba, J.M., Schimmel, B.C.J., Glas, J.J., Ataide, L.M.S., Pappas, M.L., Villarroel, C.A., Schuurink, R.C., Sabelis, M.W., Kant, M.R., 2015. Spider mites suppress tomato defenses downstream of jasmonate and salicylate independently of hormonal crosstalk. New Phytol. 205, 828-840.

Armstrong, G.A., Alberti, M., Leach, F., Hearst, J.E., 1989. Nucleotide sequence, organization, and nature of the protein products of the carotenoid biosynthesis gene cluster of Rhodobacter capsulatus. Mol. Gen. Genet. MGG 216, 254-268.

Bae, S., Kweon, J., Kim, H.S., Kim, J.-S., 2014. Microhomology-based choice of Cas9 nuclease target sites. Nat. Methods 11, 705-706.

Bai, X., Zeng, T., Ni, X.-Y., Su, H.-A., Huang, J., Ye, G.-Y., Lu, Y.-Y., Qi, Y.-X., 2019. CRISPR/Cas9-mediated knockout of the eye pigmentation gene white leads to alterations in colour of head spots in the oriental fruit fly, Bactrocera dorsalis. Insect Mol. Biol. 28, 837-849.

Bajda, S., Dermauw, W., Panteleri, R., Sugimoto, N., Douris, V., Tirry, L., Osakabe, M., Vontas, J., Van Leeuwen, T., 2017. A mutation in the PSST homologue of complex I 
(NADH:ubiquinone oxidoreductase) from Tetranychus urticae is associated with resistance to METI acaricides. Insect Biochem. Mol. Biol. 80, 79-90.

Betts, M.J., Russell, R.B., 2003. Amino acid properties and consequences of substitutions. In: Barnes, M.R., Gray, I.C. (Eds.), Bioinformatics for Geneticists. Wiley.

Blaazer, C.J.H., Villacis-Perez, E.A., Chafi, R., Van Leeuwen, T., Kant, M.R., Schimmel, B.C.J., 2018. Why do herbivorous mites suppress plant defenses? Front. Plant Sci. 9.

Bryon, A., Kurlovs, A.H., Dermauw, W., Greenhalgh, R., Riga, M., Grbić, M., Tirry, L., Osakabe, M., Vontas, J., Clark, R.M., Van Leeuwen, T., 2017. Disruption of a horizontally transferred phytoene desaturase abolishes carotenoid accumulation and diapause in Tetranychus urticae. Proc. Natl. Acad. Sci. U. S. A. 114, E5871-E5880.

Bryon, A., Wybouw, N., Dermauw, W., Tirry, L., Van Leeuwen, T., 2013. Genome wide gene-expression analysis of facultative reproductive diapause in the two-spotted spider mite Tetranychus urticae. BMC Genom. 14, 815.

Bui, H., Greenhalgh, R., Ruckert, A., Gill, G.S., Lee, S., Ramirez, R.A., Clark, R.M., 2018. Generalist and specialist mite herbivores induce similar defense responses in maize and barley but differ in susceptibility to benzoxazinoids. Front. Plant Sci. 9, 1222.

Catteruccia, F., Nolan, T., Loukeris, T.G., Blass, C., Savakis, C., Kafatos, F.C., Crisanti, A., 2000. Stable germline transformation of the malaria mosquito Anopheles stephensi. Nature 405, 959-962.

Chaverra-Rodriguez, D., Macias, V.M., Hughes, G.L., Pujhari, S., Suzuki, Y., Peterson, D.R., Kim, D., McKeand, S., Rasgon, J.L., 2018. Targeted delivery of CRISPR-Cas 9 ribonucleoprotein into arthropod ovaries for heritable germline gene editing. Nat. Commun. 9, 3008.

Chen, X., Xu, F., Zhu, C., Ji, J., Zhou, X., Feng, X., Guang, S., 2014. Dual sgRNA-directed gene knockout using CRISPR/Cas9 technology in Caenorhabditis elegans. Sci. Rep. 4, 7581.

Cho, S.W., Lee, J., Carroll, D., Kim, J.-S., Lee, J., 2013. Heritable gene knockout in Caenorhabditis elegans by direct injection of cas9-sgRNA ribonucleoproteins. Genetics 195, 1177-1180.

Concordet, J.-P., Haeussler, M., 2018. CRISPOR: intuitive guide selection for CRISPR/ Cas9 genome editing experiments and screens. Nucleic Acids Res. 46, W242-W245.

Dermauw, W., Osborne, E.J., Clark, R.M., Grbic, M., Tirry, L., Van Leeuwen, T., 2013a. A burst of $\mathrm{ABC}$ genes in the genome of the polyphagous spider mite Tetranychus urticae. BMC Genom. 14, 317.

Dermauw, W., Wybouw, N., Rombauts, S., Menten, B., Vontas, J., Grbic, M., Clark, R.M., Feyereisen, R., Van Leeuwen, T., 2013b. A link between host plant adaptation and pesticide resistance in the polyphagous spider mite Tetranychus urticae. Proc. Natl. Acad. Sci. U. S. A. 110, E113-E122.

Dickinson, D.J., Goldstein, B., 2016. CRISPR-based methods for Caenorhabditis elegans genome engineering. Genetics 202, 885-901.

Douris, V., Steinbach, D., Panteleri, R., Livadaras, I., Pickett, J.A., Van Leeuwen, T., Nauen, R., Vontas, J., 2016. Resistance mutation conserved between insects and mites unravels the benzoylurea insecticide mode of action on chitin biosynthesis Proc. Natl. Acad. Sci. U. S. A. 113, 14692-14697.

Farboud, B., Severson, A.F., Meyer, B.J., 2019. Strategies for efficient genome editing using CRISPR-cas9. Genetics 211, 431-457.

Gang, S.S., Castelletto, M.L., Bryant, A.S., Yang, E., Mancuso, N., Lopez, J.B., Pellegrini, M., Hallem, E.A., 2017. Targeted mutagenesis in a human-parasitic nematode. PLoS Pathog. 13, e1006675.

Gantz, V.M., Akbari, O.S., 2018. Gene editing technologies and applications for insects. Curr. Opin. Insect Sci. 28, 66-72.

Garb, J.E., Sharma, P.P., Ayoub, N.A., 2018. Recent progress and prospects for advancing arachnid genomics. Curr. Opin. Insect Sci. 25, 51-57.

Grbic, M., Van Leeuwen, T., Clark, R.M., Rombauts, S., Rouze, P., Grbic, V., Osborne, E.J., Dermauw, W., Ngoc, P.C.T., Ortego, F., Hernandez-Crespo, P., Diaz, I., Martinez, M., Navajas, M., Sucena, E., Magalhaes, S., Nagy, L., Pace, R.M., Djuranovic, S., Smagghe, G., Iga, M., Christiaens, O., Veenstra, J.A., Ewer, J., Mancilla Villalobos, R., Hutter, J.L., Hudson, S.D., Velez, M., Yi, S.V., Zeng, J., Pires-daSilva, A., Roch, F., Cazaux, M., Navarro, M., Zhurov, V., Acevedo, G., Bjelica, A., Fawcett, J.A., Bonnet, E., Martens, C., Baele, G., Wissler, L., Sanchez-Rodriguez, A., Tirry, L., Blais, C., Demeestere, K., Henz, S.R., Gregory, T.R., Mathieu, J., Verdon, L., Farinelli, L., Schmutz, J., Lindquist, E., Feyereisen, R., Van de Peer, Y., 2011. The genome of Tetranychus urticae reveals herbivorous pest adaptations. Nature 479, 487-492.

Gui, T., Zhang, J., Song, F., Sun, Y., Xie, S., Yu, K., Xiang, J., 2016. CRISPR/Cas9Mediated genome editing and mutagenesis of EcChi4 in Exopalaemon carinicauda. G3: Genes Genomes Genet. 6, 3757-3764.

Hunter, W.B., Gonzalez, M.T., Tomich, J., 2018. BAPC-assisted CRISPR/Cas9 System: Targeted Delivery into Adult Ovaries for Heritable Germline Gene Editing (Arthropoda: Hemiptera). bioRxiv, pp. 478743.

Iida, J., Desaki, Y., Hata, K., Uemura, T., Yasuno, A., Islam, M., Maffei, M.E., Ozawa, R., Nakajima, T., Galis, I., Arimura, G.-i., 2019. Tetranins: new putative spider mite elicitors of host plant defense. New Phytol. 224, 875-885.

Ismail, N.I.B., Kato, Y., Matsuura, T., Watanabe, H., 2018. Generation of white-eyed Daphnia magna mutants lacking scarlet function. PloS One 13, e0205609.

Jinek, M., Chylinski, K., Fonfara, I., Hauer, M., Doudna, J.A., Charpentier, E., 2012. A programmable dual-RNA-guided DNA endonuclease in adaptive bacterial immunity. Science 337, 816-821.

Jonckheere, W., Dermauw, W., Khalighi, M., Pavlidi, N., Reubens, W., Baggerman, G., Tirry, L., Menschaert, G., Kant, M., Vanholme, B., Van Leeuwen, T., 2018. A gene family coding for salivary proteins (SHOT) of the polyphagous spider mite Tetranychus urticae exhibits fast host-dependent transcriptional plasticity. Mol. Plant Microbe In. 31, 112-124.

Jonckheere, W., Dermauw, W., Zhurov, V., Wybouw, N., Van den Bulcke, J., Villarroel, C.A., Greenhalgh, R., Grbić, M., Schuurink, R.C., Tirry, L., Baggerman, G., Clark, R.M., Kant, M.R., Vanholme, B., Menschaert, G., Van Leeuwen, T., 2016. The salivary protein repertoire of the polyphagous spider mite Tetranychus urticae: a quest for effectors. Mol. Cell. Proteomics 15, 3594-3613

Kane, N.S., Vora, M., Varre, K.J., Padgett, R.W., 2017. Efficient screening of CRISPR/ Cas9-Induced events in Drosophila using a Co-CRISPR strategy. G3: Genes Genomes Genet.: Genes Genomes Genet. 7, 87-93.

Khan, S.A., Reichelt, M., Heckel, D.G., 2017. Functional analysis of the ABCs of eye color in Helicoverpa armigera with CRISPR/Cas9-induced mutations. Sci. Rep. 7, 40025.

Korona, D., Koestler, S.A., Russell, S., 2017. Engineering the Drosophila genome for developmental biology. J. Dev. Biol. 5, 16.

Kotwica-Rolinska, J., Chodakova, L., Chvalova, D., Kristofova, L., Fenclova, I., Provaznik, J., Bertolutti, M., Wu, B.C.-H., Dolezel, D., 2019. CRISPR/Cas9 genome editing introduction and optimization in the non-model insect Pyrrhocoris apterus. Front. Physiol. 10, 891.

Kurlovs, A.H., Snoeck, S., Kosterlitz, O., Van Leeuwen, T., Clark, R.M., 2019. Trait mapping in diverse arthropods by bulked segregant analysis. Curr. Opin. Insect Sci. 36, 57-65.

Kwon, D.H., Park, J.H., Ashok, P.A., Lee, U., Lee, S.H., 2016. Screening of target genes for RNAi in Tetranychus urticae and RNAi toxicity enhancement by chimeric genes. Pestic. Biochem. Physiol. 130, 1-7.

Le Trionnaire, G., Tanguy, S., Hudaverdian, S., Gleonnec, F., Richard, G., Cayrol, B., Monsion, B., Pichon, E., Deshoux, M., Webster, C., Uzest, M., Herpin, A., Tagu, D., 2019. An integrated protocol for targeted mutagenesis with CRISPR-Cas 9 system in the pea aphid. Insect Biochem. Mol. Biol. 110, 34-44.

Macias, V.M., McKeand, S., Chaverra-Rodriguez, D., Hughes, G.L., Fazekas, A., Pujhari, S. Jasinskiene, N., James, A.A., Rasgon, J.L., 2019. Cas9-mediated Gene-Editing in the Malaria Mosquito Anopheles stephensi by ReMOT Control. bioRxiv, pp. 775312.

Martel, C., Zhurov, V., Navarro, M., Martinez, M., Cazaux, M., Auger, P., Migeon, A., Santamaria, M.E., Wybouw, N., Diaz, I., 2015. Tomato whole genome transcriptional response to Tetranychus urticae identifies divergence of spider mite-induced responses between tomato and arabidopsis. Mol. Plant Microbe Interact. 28, 343-361.

Martin, A., Serano, J.M., Jarvis, E., Bruce, H.S., Wang, J., Ray, S., Barker, C.A., O'Connell, L.C., Patel, N.H., 2016. CRISPR/Cas9 mutagenesis reveals versatile roles of Hox genes in crustacean limb specification and evolution. Curr. Biol. 26, 14-26.

Mota-Sanchez, R.M., Wise, J.C., 2019. Arthropod pesticide resistance database (APRD). Available at. https://www.pesticideresistance.org/.

Muller, H.J., 1932. Further studies on the nature and causes of gene mutations. In: Proceedings of the Sixth International Congress of Genetics, vol. 1. pp. 213-255 Ithaca, New York.

Nakanishi, T., Kato, Y., Matsuura, T., Watanabe, H., 2014. CRISPR/Cas-Mediated targeted mutagenesis in Daphnia magna. Plos One 9, e98363.

Navajas, M., Lagnel, J., Gutierrez, J., Boursot, P., 1998. Species-wide homogeneity of nuclear ribosomal ITS2 sequences in the spider mite Tetranychus urticae contrasts with extensive mitochondrial COI polymorphism. Heredity 80, 742-752.

Peloquin, J.J., Thibault, S.T., Staten, R., Miller, T.A., 2000. Germ-line transformation of pink bollworm (Lepidoptera: gelechiidae) mediated by the piggyBac transposable element. Insect Mol. Biol. 9, 323-333.

Prado-Cabrero, A., Schaub, P., Díaz-Sánchez, V., Estrada, A.F., Al-Babili, S., Avalos, J., 2009. Deviation of the neurosporaxanthin pathway towards $\beta$-carotene biosynthesis in Fusarium fujikuroi by a point mutation in the phytoene desaturase gene. FEBS J. 276, 4582-4597.

Presnail, J.K., Hoy, M.A., 1992. Stable genetic transformation of a beneficial arthropod, Metaseiulus occidentalis (Acari: phytoseiidae), by a microinjection technique. Proc. Natl. Acad. Sci. U. S. A. 89, 7732-7736.

Reardon, S., 2019. CRISPR gene-editing creates wave of exotic model organisms. Nature $568,441-442$.

Riga, M., Bajda, S., Themistokleous, C., Papadaki, S., Palzewicz, M., Dermauw, W., Vontas, J., Leeuwen, T.V., 2017. The relative contribution of target-site mutations in complex acaricide resistant phenotypes as assessed by marker assisted backcrossing in Tetranychus urticae. Sci. Rep. 7, 9202.

Rozen, S., Skaletsky, H.J., 2000. Primer3 on the WWW for general users and for biologist programmers. In: Krawetz, S., Misener, S. (Eds.), Bioinformatics Methods and Protocols: Methods in Molecular Biology. Humana Press, Totowa, New Jersey, USA, pp. 365-386.

Rusk, N., 2019. Spotlight on Cas12. Nat. Methods 16, 215.

Santamaría, M.E., Hernández-Crespo, P., Ortego, F., Grbic, V., Grbic, M., Diaz, I., Martinez, M., 2012. Cysteine peptidases and their inhibitors in Tetranychus urticae: a comparative genomic approach. BMC Genom. 13, 307.

Santamaría, M.E., Martinez, M., Arnaiz, A., Ortego, F., Grbic, V., Diaz, I., 2017. MATI, a novel protein involved in the regulation of herbivore-associated signaling pathways. Front. Plant Sci. 8.

Santamaría, M.E., Martínez, M., Arnaiz, A., Rioja, C., Burow, M., Grbic, V., Díaz, I., 2019. An arabidopsis TIR-lectin two-domain protein confers defense properties against Tetranychus urticae. Plant Physiol. 179, 1298-1314.

Sanz, C., Alvarez, M.I., Orejas, M., Velayos, A., Eslava, A.P., Benito, E.P., 2002. Interallelic complementation provides genetic evidence for the multimeric organization of the Phycomyces blakesleeanus phytoene dehydrogenase. Eur. J. Biochem. 269, 902-908.

Schlachter, C.R., Daneshian, L., Amaya, J., Klapper, V., Wybouw, N., Borowski, T., Van Leeuwen, T., Grbic, V., Grbic, M., Makris, T.M., Chruszcz, M., 2019. Structural and functional characterization of an intradiol ring-cleavage dioxygenase from the polyphagous spider mite herbivore Tetranychus urticae Koch. Insect Biochem. Mol. Biol. 107, 19-30.

Scott, J.G., Michel, K., Bartholomay, L.C., Siegfried, B.D., Hunter, W.B., Smagghe, G., Zhu, K.Y., Douglas, A.E., 2013. Towards the elements of successful insect RNAi. J. Insect Physiol. 59, 1212-1221.

Sharma, A., 2017. Development of CRISPR-Cas9 Gene Drive System for Deer Tick, Ixodes scapularis, IGTRCN Peer-To-Peer Training Fellowship Report. University of Maryland, MD, USA Available at. http://igtrcn.org/wp-content/uploads/2018/01/Sharma 
IGTRCN_report_val.docx.

Snoeck, S., Kurlovs, A.H., Bajda, S., Feyereisen, R., Greenhalgh, R., Villacis-Perez, E. Kosterlitz, O., Dermauw, W., Clark, R.M., Van Leeuwen, T., 2019a. High-resolution QTL mapping in Tetranychus urticae reveals acaricide-specific responses and common target-site resistance after selection by different METI-I acaricides. Insect Biochem. Mol. Biol. 110, 19-33.

Snoeck, S., Pavlidi, N., Dermauw, W., Van Leeuwen, T., 2019. Substrate specificity and promiscuity of UDP-glycosyltransferases in the polyphagous arthropod Tetranychus urticae. Insect Biochem. Mol. Biol. 109, 116-127.

Snoeck, S., Wybouw, N., Van Leeuwen, T., Dermauw, W., 2018. Transcriptomic plasticity in the arthropod generalist Tetranychus urticae upon long-term acclimation to different host plants. G3: Genes Genomes Genet. 8, 3865-3879.

Sumitani, M., Yamamoto, D.S., Oishi, K., Lee, J.M., Hatakeyama, M., 2003. Germline transformation of the sawfly, Athalia rosae (Hymenoptera: symphyta), mediated by a piggyBac-derived vector. Insect Biochem. Mol. Biol. 33, 449-458.

Sun, D., Guo, Z., Liu, Y., Zhang, Y., 2017. Progress and prospects of CRISPR/Cas systems in insects and other arthropods. Front. Physiol. 8, 608.

Suzuki, T., Nunes, M.A., España, M.U., Namin, H.H., Jin, P., Bensoussan, N., Zhurov, V., Rahman, T., De Clercq, R., Hilson, P., Grbic, V., Grbic, M., 2017. RNAi-based reverse genetics in the chelicerate model Tetranychus urticae: a comparative analysis of five methods for gene silencing. PloS One 12, e0180654.

Van Leeuwen, T., Demaeght, P., Osborne, E.J., Dermauw, W., Gohlke, S., Nauen, R., Grbic, M., Tirry, L., Merzendorfer, H., Clark, R.M., 2012. Population bulk segregant mapping uncovers resistance mutations and the mode of action of a chitin synthesis inhibitor in arthropods. Proc. Natl. Acad. Sci. U. S. A. 109, 4407-4412.

Van Leeuwen, T., Dermauw, W., 2016. The molecular evolution of xenobiotic metabolism and resistance in Chelicerate mites. Annu. Rev. Entomol. 61, 475-498.

Van Leeuwen, T., Tirry, L., Yamamoto, A., Nauen, R., Dermauw, W., 2015. The economic importance of acaricides in the control of phytophagous mites and an update on recent acaricide mode of action research. Pestic. Biochem. Physiol. 121, 12-21.

Villarroel, C.A., Jonckheere, W., Alba, J.M., Glas, J.J., Dermauw, W., Haring, M.A., Van Leeuwen, T., Schuurink, R.C., Kant, M.R., 2016. Salivary proteins of spider mites suppress defenses in Nicotiana benthamiana and promote mite reproduction. Plant J. 86, 119-131.

Witte, H., Moreno, E., Rödelsperger, C., Kim, J., Kim, J.-S., Streit, A., Sommer, R.J., 2015.
Gene inactivation using the CRISPR/Cas9 system in the nematode Pristionchus pacificus. Dev. Gene. Evol. 225, 55-62.

Wybouw, N., Balabanidou, V., Ballhorn, D.J., Dermauw, W., Grbić, M., Vontas, J., Van Leeuwen, T., 2012. A horizontally transferred cyanase gene in the spider mite Tetranychus urticae is involved in cyanate metabolism and is differentially expressed upon host plant change. Insect Biochem. Mol. Biol. 42, 881-889.

Wybouw, N., Dermauw, W., Tirry, L., Stevens, C., Grbic, M., Feyereisen, R., Van Leeuwen, T., 2014. A gene horizontally transferred from bacteria protects arthropods from host plant cyanide poisoning. Elife 3, e02365.

Wybouw, N., Kosterlitz, O., Kurlovs, A.H., Bajda, S., Greenhalgh, R., Snoeck, S., Bui, H., Bryon, A., Dermauw, W., Van Leeuwen, T., Clark, R.M., 2019. Long-term population studies uncover the genome structure and genetic basis of xenobiotic and host plant adaptation in the herbivore Tetranychus urticae. Genetics 211, 1409-1427.

Wybouw, N., Van Leeuwen, T., Dermauw, W., 2018. A massive incorporation of microbial genes into the genome of Tetranychus urticae, a polyphagous arthropod herbivore. Insect Mol. Biol. 27, 333-351.

Wybouw, N., Zhurov, V., Martel, C., Bruinsma, K.A., Hendrickx, F., Grbić, V., Van Leeuwen, T., 2015. Adaptation of a polyphagous herbivore to a novel host plant extensively shapes the transcriptome of herbivore and host. Mol. Ecol. 24, 4647-4663.

Xue, W.-H., Xu, N., Yuan, X.-B., Chen, H.-H., Zhang, J.-L., Fu, S.-J., Zhang, C.-X., Xu, H.-J., 2018. CRISPR/Cas9-mediated knockout of two eye pigmentation genes in the brown planthopper, Nilaparvata lugens (Hemiptera: Delphacidae). Insect Biochem. Mol. Biol. 93, 19-26.

Zhang, L., Reed, R.D., 2017. A practical guide to CRISPR/Cas9 genome editing in Lepidoptera. In: Sekimura, T., Nijhout, H.F. (Eds.), Diversity and Evolution of Butterfly Wing Patterns: an Integrative Approach. Springer Singapore, Singapore, pp. $155-172$.

Zhurov, V., Navarro, M., Bruinsma, K.A., Arbona, V., Estrella Santamaria, M., Cazaux, M., Wybouw, N., Osborne, E.J., Ens, C., Rioja, C., Vermeirssen, V., Rubio-Somoza, I., Krishna, P., Diaz, I., Schmid, M., Gomez-Cadenas, A., Van de Peer, Y., Grbic, M., Clark, R.M., Van Leeuwen, T., Grbic, V., 2014. Reciprocal responses in the interaction between Arabidopsis and the cell-content-feeding chelicerate herbivore spider mite. Plant Physiol. 164, 384-399. 